\title{
Síndrome da Má-Adaptação ao Trabalho em Turnos - uma Abordagem Ergonômica
}

\author{
Gilsée Ivan Régis Filho \\ Universidade Federal de Santa Catarina \\ Professor do Departamento de Estomatologia \\ Dr. Engenharia de Produção \\ gmregis@melim.com.br
}

O sistema de trabalho em turnos e noturno por ir contra a natureza humana, eminentemente diurna, traz prejuízos para a saúde do trabalhador tanto nos aspectos físicos e psíquicos, como emocionais e sociais. As manifestaçōes agudas como insônia, excessiva sonolência durante o trabalho, distúrbios de humor, aumento de acidentes e problemas familiares e as manifestaçōes crônicas como desordens do sono, doenças cardiovasculares e gastrointestinais, separação e divórcio, compõem os sinais e sintomas da Síndrome da Má-adaptação ao Trabalho em Turnos. O presente trabalho teve por objetivos analisar a Síndrome da Má-adaptação ao Trabalho em Turnos e o Trabalho Noturno e apresentar um estudo de caso onde através de questionários foram pesquisados aspectos de cronobiologia, variáveis biológicas e psicossociais relacionadas com o trabalho em turnos e noturno em uma empresa do setor cerâmico de Santa Catarina que utiliza o sistema de trabalho em turnos não rodiziantes. O estudo de caso revelou que em média 1 em cada 5 trabalhadores apresentaram pelo menos um dos sintomas de inadaptação ao trabalho em turnos e noturno e que pelo menos $10 \%$ dos trabalhadores manifestaram sintomatologia característica da Síndrome da Má-adaptação ao Trabalho em Turnos.

Palavra-chave: Trabalho noturno, trabalho em turnos, organização do trabalho.

The shiftwork and nightwork system, for going against human nature, wich is eminently a day one, harms a worker's health from a physical, psychic, emotional and social point of view. Acute manifestations such as isomnia, excessive sleepness during work hours, changes of humor, increased rates of accidents and family problems, as well as chronic manifestations as sleep disorders, cardiovascular and gastrointestinal diseases, separation and divorce, make up signs and symptoms of Shiftwork Maladaptation Syndrome. This work sought to investigate Shiftwork Maladaptation Syndrome, and to analyze Night Work. By means of questionnaires, chronobiology aspects, biological and psicossocial variables have been researched such as related to shift and night work in a Santa Catarina enterprise working with ceramic products, where a non - rotatory shift work system is employed. The study of the case showed that 1 in 5 workers presented at least one of maladaptation symptoms when placed on shift and night work, and that at least $10 \%$ at workers exhibited symptomatology identified with shiftwork maladaptation syndrome.

Keywords: Shiftwork maladaptation syndrome, shiftwork, nightwork.

\section{INTRODUÇÃO}

\section{A Organização Mundial da Saúde conceitua saúde} como "o completo estado de bem estar físico, psíquico $e$ social". Poderíamos agregar a este conceito que saúde é qualidadè de vida, sendo também, o resultado do total funcionamento do individuo em seu ambiente, ou segundo Laville \& Volkoff (1993) citado por Falzon (1996): "Saúde é a ausência de estados, como: patologia, deficiência, restrição da vida social e miséria econômica", ou seja, saúde deve ser vista preferencialmente como o resultado de um processo de construção de uma vida saudável ou, ainda, a adoção de práticas adequadas de cuidados médicos, de higiene pessoal, de prevenção contra doenças, de prevenção de acidentes e de equilíbrio das atividades diárias: trabalho, recreação, sono e repouso. Assim, há várias dimensões da vida do ser humano e da chamada saúde total de uma pessoa: física, social, emocional, intelectual, espiritual $e$ ocupacional, ou seja, o trabalho $e$ as condições em que este trabalho é realizado são fatores preponderantes no estado de saúde integral do individuo.

Durante todo o processo de organização industrial, da passagem do sistema artesanal ou familiar para o sistema fabril de produção, as condições de vida no trabalho não receberam a devida atenção. $\mathrm{Na}$ Inglaterra do início do século XVIII eram fatos considerados 
normais, no rigor das primeiras fábricas, os fiandeiros trabalharem 14 horas por dia à uma temperatura de 26 a $29^{\circ} \mathrm{C}$ sem terem permissão para buscar água. Da mesma forma, no sistema doméstico de produção, aqui entendido sistema produtivo artesanal, também fazia parte da rotina das pessoas, as longas jornadas de trabalho e a exploração do trabalho infantil - com crianças de 7 a 11 anos de idade trabalhando como aprendizes das 5 horas da manhã até as 20 horas em turnos de 15 horas, para Huberman (1986).

Entretanto, não somente nas fábricas o aspecto da qualidade de vida era relegado a um segundo plano. Registros atestam que nos Estados Unidos na década de 30, o trabalho artesanal realizava-se invariavelmente em casas sujas, superlotadas e com comida insatisfatória. Crianças com menos de 16 anos trabalhavam, em praticamente todas as familias, executando trabalho doméstico, sendo que metade delas tinha idade inferior a 12 anos, segundo Huberman (1986).

Num mundo em constante mudança, de economia globalizada e de mercados emergentes, modernas tecnologias gestoriais têm oportunizado melhorias consideráveis na forma de como as empresas podem tornar-se altamente competitivas e obter ganhos consideráveis de produtividade. Porém, pouca ou nenhuma atenção é dada à qualidade de vida no trabalho, sendo que normalmente postos de trabalho são, na verdade, postos de tortura, o que não é um privilégio da era moderna, mas sim uma cultura que acompanha todas as fases da introdução do sistema capitalista.

O trabalho inserido dentro do contexto social descortinase como elemento essencial na construção do indivíduo, embora a vida não se resuma ao trabalho. A mesma não pode ser entendida na sua ausência, e o trabalho fazendo parte da vida do ser humano não pode ser causa de seu sofrimento físico, psíquico e emocional.

Umas das formas de organização temporal do trabalho é a realizada em turnos e noturno, ou seja "o trabalho sendo realizado em diferentes horários ou em horário constante, porém, incomum (por exemplo, o período noturno permanente). O turno resulta sempre do fato de que a mesma atividade deva ser executada em diferentes períodos do dia e da noite, por vários empregados, em igual jornada" Rutenfranz, Knauth \& Fischer (1989).

O trabalho em turnos e noturno é responsável nos países desenvolvidos por cerca de $20 \%$ do nível de emprego e, aproximadamente, metade desse trabalho em turnos sendo realizado no turno noturno e o labor noturno não rodiziante correspondendo a $1 / 3$ de todo o trabalho $\mathrm{em}$ turnos, segundo Maurice (1975), Tavemier (1978) $e$ Harrington (1994).

Scott \& LaDou (1994) afirmam que pelo menos 20 milhöes de pessoas nos EUA trabalham em horário não-padronizado, ou seja não compreendido entre às 8:00 e às 18:00 horas, sendo que dois milhões são trabalhadores noturnos, cerca de 3 milhões fazem rotação de turnos que podem incluir trabalho noturno e quase $16 \%$ dos trabalhadores em tempo integral são trabalhadores de turnos.

Nos EUA alguns setores têm um percentual bem mais alto de trabalhadores em trabalho em turnos e noturno. Indústrias de capital intensivo e operações de processo contínuo podem ter $50 \%$ dos empregados trabalhando em um $2^{\circ}$ ou $3^{\circ}$ turno. Mais de $1 / 4$ dos operadores de veículos motores em tempo integral é trabalhador de turnos, com cerca da metade em turnos da noite ou em rodízio. Mais de $38 \%$ daqueles em ocupações de serviço é trabalhador de turnos, Scott \& LaDou (1994).

À medida que a economia dos EUA e de muitos países desenvolvidos e em desenvolvimento, entre eles o Brasil, se torna crescentemente orientada à prestação de serviços $e$ à indústria, o número de trabalhadores designados para horários de trabalho considerados fora do padrão continuará a aumentar.

A organização temporal do trabalho em turnos $e$ noturno traz inegáveis prejuízos para a saúde do trabalhador, tanto no aspecto físico, como psíquico, emocional e social, sendo alguns bastante conhecidos $e$ outros, ainda, necessitando de maior investigação, bem como tarefas que resultem em esforços adicionais, em virtude da organização do trabalho, deixam marcas indeléveis no trabalhador, como as manifestações psicossomáticas.

O trabalho em turnos e noturno, ao provocar redução do estado de vigília, afeta a produtividade e a segurança, custando às companhias americanas, que dependem desta forma organizacional do trabalho, cerca de 70 bilhões de dólares por ano, dados fornecidos por Scott \& LaDou (1994).

A configuração da força de trabalho está mudando em diversos países, inclusive nos EUA, tendo em vista que para o próximo século as previsões, com base em 
tendências, são que a massa trabalhadora será mais idosa e mais feminina, submetendo um maior percentual de trabalhadores a um maior risco de que algum impacto negativo sobre sua saúde ocorra devido aos seus horários de trabalho, segundo Scott \& LaDou (1994).

O trabalho em turnos e noturno pode ser causa de uma série de distúrbios, pois $30 \%$ dos trabalhadores de turnos se queixam de sintomas de gastrite, das doenças cardiovasculares relacionadas com trabalho $7 \%$ delas são atribuídas ao trabalho em turnos e noturno, havendo, também, uma conexão entre pertubação do sono $e$ hipertensão arterial em trabalhadores noturnos, colocando os mesmos sob risco de doença coronariana. Parece haver evidências que a estimativa de vida dos trabalhadores em turnos é $10 \%$ menor que os outros trabalhadores diurnos, Thiis-Evensen (1958), Cipolla Neto, Marques \& Menna-Barreto (1988), Knutsson, Akerstedt \& Jonsson (1988) e Olsen \& Kristensen (1991).

Por outro lado, os problemas e conflitos decorrentes do trabalho em turnos e noturno não se ligam unicamente às mudanças de ritmos biológicos e parâmetros fisiológicos, mas sim, e fortemente, a uma dessincronização familiar e social, como afirmam Koller, Kundi, Haider et al (1990).

$O$ trabalho em turnos e noturno (rodiziante ou não), como parece evidente, pode ser responsável por inúmeros distúrbios fisiológicos e psicossociais, transformando-se em uma das mais perversas formas de organização temporal do trabalho, constituindo seus sintomas imediatos e de longo prazo, numa verdadeira Síndrome da Má-adaptação ao Trabalho em Turnos.

As manifestações agudas dentro do primeiro mês de exposição ao sistema de trabalho em turnos e noturno são caracterizadas por insônia, excessiva sonolência durante o trabalho, distúrbios do humor, aumento de acidentes e problemas familiares, sociais e emocionais. Após cinco anos neste sistema de trabalho, o indivíduo passa a apresentar manifestações crônicas ligadas a desordens do sono, doenças cardiovasculares $e$ gastrointestinais, absenteísmo, separação e divórcio, Moore-Ede, Krieger \& Darlington (1987).

$O$ trabalhador ao inverter o ciclo sono-vigília em decorrência do trabalho noturno, ou seja, dormir durante o dia e trabalhar à noite, induz a uma dessincronização interna dos ritmos biológicos $e$ circadianos, bem como favorece conflitos de ordem social, pois nossa cultura é predominantemente diurna.

As origens destes conflitos e distúrbios podem ser encontradas no fato que o ser humano é fisiologicamente preparado para a rotina diurna, sendo que a mesma é determinada geneticamente e governada por osciladores endógenos e exógenos, tanto ambientais como sociais.

$A$ inadaptabilidade ao trabalho em turnos $e$,

principalmente noturno, gera muitas vezes o uso abusivo de substâncias para dormir e de álcool, bem como fadiga crônica e manifestações de estresse.

A existência do trabalho em turnos e noturno, uma necessidade muitas vezes intrínseca ao próprio processo produtivo ou uma resposta ao aumento da demanda $e$, embora não havendo, a priori, solução única e ideal para este tipo de sistematização da produção, deve ser uma preocupação constante, para permitir soluções melhores para a organização temporal do trabalho.

O trabalho, inerente à própria condição humana, como fator de equilibrio, desenvolvimento do ser humano $e$ fonte de prazer, motivação e satisfação, não tem, muitas vezes, conseguido proporcionar à grande massa de trabalhadores oportunidades para seu equilíbrio psíquico e físico.

$A$ atividade profissional deixa traços sobre o organismo ao longo da sua duração. Não se pode, com efeito, conceber a existência de uma evolução com a idade do trabalhador sem relação com as condições nas quais esse organismo vive, ou seja, condições de trabalho as quais o ser humano é submetido durante grande parte de sua vida até o seu abandono por aposentadoria ou por algum tipo de patologia, tanto física como psíquica ou emocional.

Certos traços, provocados pelo trabalho, são imediatamente identificáveis, tais como, os acidentes do trabalho ou as doenças profissionais, porém outros são mais hipotéticos que prováveis e muitas vezes difíceis de correlacionar porque são inespecíficos. São, segundo Teiger, Laville \& Lortie (1981), linhas probabilisticas que necessitam de estudos epidemiológicos que muitas vezes não podem colocar em evidência os efeitos a longo tempo, 5 anos ou mais, das condições de trabalho sobre o ser humano.

Por outro lado, as empresas ao buscar maior produtividade e melhor qualidade dos seus produtos privilegiaram métodos e processos em detrimento do fator 
humano, deixando de atender às necessidades básicas as pessoas, sendo que esse ambiente refletiu-se no desenvolvimento da organização temporal do trabalho em geral e do trabalho em turnos e noturno em particular.

\section{CRONOBIOLOGIA, VARIÁVEIS BIOLÓGICAS E PSICOSSOCIAIS E O TRABALHO EM TURNOS E NOTURNO}

\subsection{CRONOBIOLOGIA}

Em 1729 o astrônomo francês Jean-Jacques D'Ortous De Marian, segundo Suarez (1990), já suspeitava da existência de relógios biológicos. Observou que uma planta, a heliotropo mimosa-sensitiva, colocada próxima ao seu telescópio abria conforme a luminosidade, ou seja, tinha um ritmo endógeno e abria suas folhas durante o dia e as fechava durante a noite. De Marian, curioso com o fato, isolou o vaso dentro de um baú, que se encontrava no porão da casa. Verificou que mesmo nessas condições de total escuridão a planta continuava a se movimentar como se acompanhasse o dia e a noite.

Para Cipolla Neto, Marques \& Menna-Barreto (1988) os ritmos são herdados, ou seja, fazem parte do patrimônio genético, como afirma Chade (1986), e os fatores ambientais servem apenas para ajustar os ponteiros dos relógios biológicos.

Assim, como o calor alterna com o frio, a chuva substitui a seca, dias claros afastam dias cinzentos, refletindo a caminhada da terra ao redor do sol, a vida também se altera a cada estação, mudando o comportamento das espécies, que tratam de sobreviver da melhor maneira, como as plantas que em certa época germinam, em outra desabrocham e em outra ainda perdem as folhas, enquanto os animais migram em certos meses e em outros se acasalam.

Os seres vivos também se adaptaram à alternância diária de luz e escuridão. Se há plantas que reservam para a fotossintese os horários em que a luz é ideal, alguns insetos, como as abelhas por sua vez, fazem seus vôos quando as flores liberam mais pólen, algo que elas perceberm através de uma diferença na luminosidade do ambiente.

Em todas as espécies há fenômenos semelhantes por se repetirem com a regularidade de um relógio, de um calendário ou de um ritmo.
Os mamíferos de maneira geral, e os seres humanos em particular, não são exceção, têm uma ritimicidade natural para muitas funções corporais, seguem um comportamento periódico. São os ritmos biológicos que podem ser de três tipos, conforme sua freqüência, de acordo com Fraisse (1980), Ferreira (1987), Arechiga (1988), Suarez (1990) e Scott \& LaDou (1994): a) circadiano, do latim - circadien - cerca de um dia (com freqüencia próxima das 24 horas), termo criado por Halberg, Halberg, Barnum \& Bittterer em 1959, de acordo com Scott \& LaDou (1994); b) ultradiano (freqüência maior que no ritmo circadiano - ciclos com duração de milionésimos de segundos até algumas horas, sempre inferior a 24 horas); e c) infradiano (com freqüência menor que no ritmo circadiano - ciclos com duração superior a 24 horas).

Múltiplas funções fisiológicas, psicológicas $e$ comportamentais seguem ritmos circadianos, tais como, temperatura corporal, corticosteróides e eletrólitos do soro e urinários, funções cardiovasculares, secreção de enzimas gástricas, número de leucócitos do sangue, força muscular, estado de alerta, humor e memória imediata e à longo prazo, de acordo com Scott \& LaDou (1994).

Para Reinberg, Chaumont, Laport et al (1973) e Suarez (1990) cada célula nervosa, glandular, digestiva,

hepática, etc. tem seu próprio ritmo circadiano, pois são bem ativas em certas horas e estão em repouso em outras. Sincronizam-se entre elas e estão acopladas a um relógio biológico mestre e este ao meio ambiente por sincronizadores ambientais.

Essas variações são periódicas e previsíveis, tanto que se pode representá-las como funçöes sinoidais com um ápice que se situa a uma certa hora e um momento de inatividade que se situa doze horas mais cedo ou doze horas mais tarde. Os picos dessas diversas variações fisiológicas não são distribuídos por acaso. Sua distribuição no tempo, no curso das vinte e quatro horas, forma um todo harmonioso. O conjunto dessas variações é descrito pelo nome de estrutura temporal do organismo, segundo Reinberg, Chaumont, Laport et alii (1973).

Os ritmos circadianos como o ciclo sono/vigília, a temperatura do corpo, a taxa respiratória, a excrę̧ão urinária, a divisão celular e a produção de hormônios podem, ainda, ser modulados por fatores exógenos, tais como, ciclo luz/escuridão, sociais, culturais, climáticos, horários de trabalho/descanso, etc., Harrington (1994). 
Assim como pode a estrutura temporal interna ter uma característica hereditária específica, pode essa estrutura temporal interna ser alterada ou modificada pelas mudanças de sincronizadores ambientais.

Os ritmos ultradianos, como o intervalo de 90 a 100 minutos entre as repetições do movimento rápido dos olhos na fase do Sono Paradoxal, bem como os ritmos infradianos, como por exemplo, os ciclos menstruais das mulheres, são também modulados por fatores exógenos. Os ritmos biológicos só podem ser alterados quando podemos alterar os ZEITGEBERS ou sincronizadores externos, segundo Scott \& LaDou (1994).

Sair para o trabalho em determinada hora, almoçar sempre ao meio-dia, descansar ao menos uma vez por semana, todas as pessoas tem noção dos ritmos necessários ao funcionamento da vida em sociedade. Porém poucos percebem a rotina interna do organismo, onde cada função tem um ritmo próprio,

determinando, por exemplo, momentos do dia em que $o$ indivíduo se sente mais disposto e outros em que, fica mais vulnerável a doenças.

A maioria dos ciclos biológicos se dá num periodo de 25,2 horas, existindo diferenças de pessoa para pessoa, pois a zero hora de uma não é necessariamente a da outra.

Existem aqueles que acordam e dormem cedo, são os indivíduos classificados como matutinos, enquanto outros preferem ir para cama por volta das 3 horas da madrugada, para acordar perto do meio-dia; são os vespertinos, Cipolla Neto, Marques \& Menna-Barreto (1988).

Esse aspecto é de extrema relevância, pois os ciclos de todas as funções são arrastados pelo ciclo do sono. Assim, os estímulos externos servem apenas para sincronizar os ritmos internos com o ambiente, pois o organismo não se comporta à noite como de dia, não importando aí o fato de se estar acordado ou dormindo.

Entre os sincronizadores dos seres humanos, as relações sociais - família, trabalho e lazer - apresentam características mais particulares. O maior sincronizador social do recém nascido ou do lactente é a alternância da presença e ausência da mãe, no entender de Chade (1986).

A luz, porém, é o sincronizador mais relevante para a maioria dos seres vivos. Por exemplo, impressionadas pela luminosidade, as células da retina disparam através dos nervos óticos uma mensagem elétrica que alcança o hipotálamo, na base do cérebro. O hipotálamo, além de comandar as glândulas do organismo, possui um pequeno núcleo onde se localiza o relógio biológico, considerado essencial à manutenção dos ritmos.

A glândula pineal, localizada na área dorsal do cérebro $e$ comandada pelo hipotálamo, tem sua função regulada pela luminosidade do dia que impede a glândula de produzir a melatonina. Quando chega à noite a glândula pineal é desbloqueada, pois a luz artificial é muito fraca para produzir o mesmo efeito, começando a liberar seu hormônio que, além de induzir o sono, age como uma espécie de indicador para todos os outros ritmos biológicos. Se um nível ótimo de melatonina não é produzido no período próprio, o trabalhador não poderá experimentar uma qualidade de sono adequada.

Para Cipolla Neto, Marques \& Menna-Barreto (1988) e Suarez (1990) o organismo compreende que existe um momento antes e um momento depois da produção da melatonina, regulando diversas funções metabólicas a partir da liberação deste hormônio e que exerce papel na fisiopatologia dos transtornos da puberdade $e$ convulsões. A melatonina ainda estimula certas células imunológicas que combatem tumores, os quais se desenvolvem mais depressa durante o dia.

Paralelamente, algumas horas após o início da produção de melatonina, outra glândula, a hipófise, começa a secretar o chamado hormônio do crescimento, cujo pico no organismo se dá por volta das 3 horas da madrugada. Esse hormônio é responsável pela renovação das células, um processo que se repete noite após noite,

ritmicamente. Por outro lado, outro hormônio, o cortisol é produzido pelas glândulas supra-renais pouco antes da pessoa despertar e prepara o organismo para a atividade, aumentando a resistência ao estresse físico, Guyton (1993). Por isso exercícios pela manhã cansam menos do que à noite, quando o cortisol não é produzido, Cipolla-Neto, Negrão, Afeche et al (1988).

A corticotrofina ou hormônio adrenocorticotrópico (ACTH) tem seu padrão semelhante ao cortisol, ou seja, níveis mais baixos nas horas iniciais do sono e mais altos na porção final, preparando o organismo para a vigília, para Suarez (1990).

A corticotrofina estimula a secreção de hormônios do córtex supra-renal, principalmente glicocorticóides $e$ mantém a integridade da mesma, Zanini \& Oga (1985).

Weibel, Brandenberger, Goichot at al (1995) afirmam 
atividade nas áreas cerebrais responsáveis pela atenção. A

haver um padrão circadiano na produção de tirotropina, havendo uma lenta elevação durante o entardecer, um pico ao redor da hora do início do adormecer e uma subseqüente diminuição durante o sono, sendo que valores baixos são encontrados durante o dia. Parece haver um papel modulatório da tirotropina para o sono.

Por outro lado, a tirotropina controla totalmente a secreção da glândula tireóide. Quando este hormônio deixa de ser secretado a glândula tireóide praticamente deixa de produzir qualquer hormônio, Guyton (1993).

A produção da prolactina é episódica, pulsátil, relacionada com o sono. Os níveis mais altos são encontrados entre as cinco e sete horas da manhã, sendo que a inversão total ou parcial do ciclo sono/vigília causa uma alteração imediata na secreção da prolactina, Suarez (1990).

Como a prolactina associada a outros hormônios promove o desenvolvimento do tecido mamário durante a gestação e estimula a produção de leite durante o pósparto, trabalhadoras gestantes e nutrizes deveriam abandonar, pelo menos temporariamente, o trabalho em turnos e noturno, em virtude das evidências de que este sistema de trabalho possa provocar alterações na lactação.

Um sincronizador poderoso para o ser humano é a alternância de repouso e atividade, seguindo um ciclo de vinte e quatro horas, ou seja, a relativa estabilidade de nossa estrutura temporal depende, em larga escala, da estabilidade de alternância de repouso e atividade, ligada a nossa vida social.

Uma mudança de fase dos sincronizadores sócioecológicos, de mais ou menos cinco horas, como por exemplo, traduzir-se-ia por uma mudança de fase dos picos das variáveis fisiológicas que servem para descrever nossa estrutura temporal circadiana. O resultado seria uma dessincronização do organismo, para Reinberg, Chaumont, Laport et al (1973). Essa configuração pode ser encontrada, em particular, nas horas de horário de atividade e repouso e ligadas às mudanças de horário de trabalho e viagens aéreas e que ultrapassem vários fusos horários, Reinberg, Andlauer \& Vieux (1981) e Foret (1992).

A alternância dos níveis hormonais constitui os ritmos biológicos, que influem na disposição do ser humano. Algumas pessoas experimentam indisposição entre às 13 $e$ às 15 horas e que não tem a ver com o fato de ter ingerido ou não alimentação de difícil digestão.

$\mathrm{Na}$ realidade tal fenômeno tem a ver com a baixa fome tampouco aparece casualmente no meio do dia e à noite. É que nesses períodos o aparelho digestivo já está preparado, pois produziu enzimas.

Em virtude desse ritmo biológico é importante se manter os horários das refeições, pois quando isso não ocorre, o alimento encontra o estômago despreparado e, por mais leve que seja, acarreta má digestão. Além disso, na falta do que digerir, as enzimas produzidas pelo relógio biológico ataca o próprio aparelho digestivo, propiciando o aparecimento de desordens gastrointestinais, como azia, gastrite e úlceras.

Assim, praticamente todo o organismo funciona em ritmos, inclusive a dor, variando somente de intensidade. A dor é mais suportável pela manhã do que à tarde quando as células nervosas estão mais ativas. Por outro lado, a madrugada é a hora em que a sensação dolorosa é mais intensa, pois nesse período dá-se uma queda no sistema imunológico, como praticamente de todo o metabolismo basal, e os processos inflamatórios tendem a se acentuar enquanto se dorme.

Para Ferreira (1987) há uma certa ordem temporal interna, em virtude do sincronismo dos diversos ritmos entre si e modulada pelos sincronizadores externos.

Com a inversão do horário de trabalho o indivíduo continua a sofrer influências dos indicadores de tempo (vida familiar, social e cultural), ficando então sujeito ao conflito dos sincronizadores, o organismo tentando ajustar os ritmos biológicos a uma nova reordenação $e$ sua vida de relação social tentando manter a situação anterior.

Quando se inverte o ciclo sono/vigília, ou seja, se dorme de dia e se trabalha à noite haverá uma desordem temporal, segundo Ferreira (1987) citando Alchoff (1978).

Por outro lado, a inversão do ciclo sono/vigília não induz o organismo a uma inversão de todos os outros ciclos na mesma velocidade, o que contribui para aumentar a desordem temporal $e$ agravar os sintomas de inadaptação ao programa de turnos e ao trabalho noturno com o aparecimento de diversas patologias.

$\mathrm{Na}$ realidade, os ciclos não se invertem totalmente. $\mathrm{O}$ que ocorre é uma diminuição da amplitude dos mesmos e, segundo Härmã, Takola, Akerstedt et al (1994), a idade também diminuiria a amplitude de 
muitos ritmos circadianos, aumentando os efeitos adversos sobre a saúde do trabalhador submetido ao sistema de trabalho em turnos e noturno, incluindo aí o ritmo da melatonina que contribuiria para a evolução da dessincronização interna.

Segundo Cipolla Neto, Marques \& Menna-Barreto (1988) parece haver uma desconexão entre os ciclos e o tempo. Para os autores, no caso dos trabalhadores noturnos, onde os ritmos não se invertem totalmente, a aceleração do envelhecimento seria conseqüência e não causa desse desajuste.

\subsection{CICLO SONO/VIGÍLIA}

Para melhor se entender o ciclo do sono, basicamente três critérios devem ser avaliados: atividade elétrica do córtex cerebral (como medida pelo eletroencefalograma EEG), grau de facilidade com que o indivíduo pode ser acordado e o tônus muscular.

Em um indivíduo relaxado e com olhos fechados, a atividade no EEG é de ondas grandes e lentas (ondas alfa), sendo que nas pessoas alertas e com olhos abertos, a atividade no EEG é mais dessincronizada, ou seja o mesmo apresenta ondas de amplitude menor (ondas beta).

$O$ ciclo do sono divide-se em 5 fases: $1^{\mathbf{a}}$ Fase - Com o início da sonolência há uma diminuição global da amplitude das ondas (ondas teta), caracterizando a primeira fase do sono; $2^{\text {a }}$ Fase - Aparecem episódios de atividade de alta freqüência, fusos do sono, ondas grandes e lentas de ocorrência ocasional (ondas delta). É a fase do sono caracterizado; $3^{\mathbf{a}}$ Fase - Caracteriza-se pela freqüência com que ocorrem as ondas delta $e$ manutenção do tônus muscular; $4^{\text {a }}$ Fase - Há o sono profundo, dominado pelas ondas lentas (ondas delta), redução da facilidade de acordar, com diminuição do tônus muscular, diminuição de 10 a $30 \%$ da freqüência cardíaca e respiratória e redução da pressão arterial, bem como do metabolismo basal. Esta fase é chamada de Sono de Ondas Lentas - SOL (Slow Wave Sleep - SWS). É o sono repousante considerado de recuperação física; $e$ $5^{\text {a }}$ Fase - A última fase caracteriza-se pelo sono de movimentos rápidos dos olhos (Rapid Eye Movement REM), onde o EEG é semelhante ao de uma pessoa acordada e relaxada, freqüência cardíaca e respiratória, bem como a pressão arterial aumentada, porém com baixo tônus muscular. Esta fase é conhecida como Sono Paradoxal - SP, pois é um paradoxo a pessoa estar dormindo e manter acentuada atividade cerebral, sem ter conhecimento do que a cerca. Nessa quinta fase os indivíduos são difíceis de acordar, embora possam acordar espontaneamente com mais freqüência do que nas fases mais profundas de sono de ondas lentas (SOL). Sonham, o que ocorre também na fase anterior, porém, em geral, não se lembram posteriormente, ou seja, não há consolidação dos sonhos na memória. O sono REM está relacionado com a recuperação psíquica.

O Sono Paradoxal decresce de cerca de $50 \%$ na infância para $25 \%$ na meia-idade e podendo ter até menos de $20 \%$ na velhice. Existem assim, basicamente, dois tipos de sono: Sono de Ondas Lentas (SOL) e Sono Paradoxal (SP), sendo que a maior parte do sono de cada noite é da variedade de ondas lentas.

Observa-se durante o sono, ciclos de 90 a 100 minutos de duração, onde as fases se sucedem diversas vezes, em torno de 5 a 6 ciclos, sendo que a fase do SP tem maior extensão na segunda metade do ciclo de repouso - de alguns minutos até 20 minutos - aumentando com o transcorrer da noite.

Entretanto, o padrão do sono do ser humano é variável em função da idade, sendo que a duração e quantidade total do sono ocorrida durante a quarta fase, diminuem com a mesma, o mínimo ocorre na meia-idade.

Segundo Silva Filho E Turnes (1995) há uma forte dependencia entre a qualidade do sono e a qualidade da vigília, ou seja, não dormir ou dormir mal se traduz em dificuldades para cumprir as atividades que requerem uma vigilancia intensa elou resistente.

De acordo com Foret (1984) os horários de trabalho, que impedem os individuos de dormir nos horários habituais, são fatores que lesam consideravelmente o equilíbrio psicofisiológico dos trabalhadores.

Normalmente o primeiro turno subtrai algumas horas do sono noturno, o que não é compensado pela antecipação da hora de dormir, ou seja, o resultado é um prejuízo que se acumula ao longo do período de turnos matinais.

O trabalhador tem o sono que se segue após o primeiro dia de turno noturno de trabalho prejudicado, quer seja pela duração total, quantidade de Sono de Ondas Lentas, quer seja pela quantidade de Sono Paradoxal ou de regularidade nas etapas do sono. 
Durante o período de sono diurno o organismo começou a se adaptar à inversão horária. Após o retorno ao sono noturno, é necessário refazer a atitude contrária. Quanto mais a reinversão é adiada, mais difícil se torna a readaptação. Assim, rotações rápidas seriam menos prejudiciais: 2,3 ou 4 dias consecutivos num mesmo turno de trabalho não deveriam ser ultrapassados, Foret (1984).

Para Ferreira (1987) e Harrington (1994) a quantidade de sono para trabalhadores do turno noturno pode ficar reduzida em até duas horas por dia, sendo que a qualidade também fica diminuída, particularmente na fase dois e no Sono Paradoxal, ou seja, a estrutura interna do sono fica alterada, sendo que o prejuízo se acumula ao longo dos dias, levando a um débito constante do sono.

Ferreira (1987) ressalta que os trabalhadores do primeiro turno, quando este começa em torno das 5 cinco horas, têm prejudicada sua fase de Sono Paradoxal, pois perdem a parte final do mesmo em virtude de terem de acordar muito cedo para chegarem ao trabalho.

\subsection{TEMPERATURA CORPORAL, DESEMPENHO E CARGA COGNITIVA}

Na década de 60, segundo Scott \& LaDou (1994) citando Kleitman (1963), propôs-se haver uma relação causal entre a temperatura e a melhor hora para o desempenho de certas tarefas, essencialmente tarefas do tipo de processamento imediato, como separar cartas, cópia de sílabas, multiplicação, transcrever carta para códigos, etc.

Fischer (1981), ao analisar os trabalhos de Colquhoun (1970), Bonjer (1960), Colquhoun, Blake \& Edward (1969) e Hawkins \& Armstrong-Esther (1978), concluiu que a temperatura do indivíduo tem variações durante as 24 horas do dia, ao redor de 1,1 a $1,2^{\circ} \mathrm{C}$ e que durante as horas de maior atividade a temperatura tende a se elevar até alcançar um pico máximo ao redor do fim da tarde ou início da noite, declinando até chegar ao ponto mínimo ou vale, na madrugada, entre 02:00 e 04:00 horas. Para a autora as curvas de temperatura mostram que não há uma completa adaptação ao trabalho noturno, pois à noite, quando as pessoas estão trabalhando suas temperaturas não alcançam os mesmos valores que os dos trabalhadores diurnos.

Para Scott \& LaDou (1994) mesmo após 21 turnos noturnos consecutivos não se encontrou uma inversão completa do ritmo da temperatura corporal, o que reforça a hipótese de que o sistema circadiano nunca se adapta totalmente ao trabalho noturno.

Fischer (1981) citando Colquhon et al (1968) $e$ Colquhon et al (1969), em uma série de estudos sobre trabalho em turnos e noturno, usando variações de horários de vigília naval (turnos de serviço) e em tarefas com carga cognitiva baixa e processamento imediato, como ocupações de sonar, manutenção e vigilância, observaram uma correlação positiva entre desempenho e temperatura do corpo, porém não sugeriram uma relação causal. Estudos que examinaram o desempenho de tarefas de busca seriada demonstraram que este tipo de desempenho paraleliza o ritmo da temperatura corporal, de acordo com Scott \& LaDou (1994).

Contudo, os ritmos de desempenho de tarefas envolvendo memória complexa não paralelizam o ritmo da temperatura corporal da forma como os ritmos simples de baixa cognitividade, repetitivos e de desempenho de tarefas de vigilância. Entretanto, indivíduos que executem tarefas que envolvam primariamente a memória imediata têm melhor desempenho pela manhã. Outros indivíduos que desenvolvem tarefas com trabalho de memória funcional, mostraram ter melhor desempenho próximo ao meio-dia, para Folkard (1975) e Folkard \& Monk (1980).

O ritmo de desempenho da recordação imediata difere daquele da memória à longo prazo, conforme demonstrado por Monk e Folkard (1978). Os autores mostraram para enfermeiras com ritmos circadianos normais orientados pelo dia, um filme de treinamento, em diferentes horários, durante o turno da noite. A recordação imediata e a memória à longo prazo foram testadas. A primeira, sobre o material do filme, foi melhor para as enfermeiras que viram o filme às 04:00 horas. $O$ teste feito 28 dias mais tarde teve resultados melhores para as enfermeiras que viram ofilme às 20:30 horas.

Para Scott \& LaDou (1994) citando Folkard, Monk, Knauth et al (1976) a carga cognitiva de uma tarefa, também afeta o ritmo de desempenho. Isto foi demonstrado quando tarefas de busca em carga de memória baixa, média, e alta foram dadas a trabalhadores de turnos, em intervalos regulares ao longo do dia de 24 horas e conforme se aumentava a carga de memória efetiva imposta pelas tarefas, o desempenho atingia um pico no início do dia. Para a tarefa mais simples, a velocidade de desempenho ficava em fase com ritmo da temperatura, ao passo que o desempenho do teste mais 
difícil ficava relacionado negativamente com o ritmo da temperatura.

Foi demonstrado que o desempenho de destreza manual leva mais tempo para se ajustar a mudanças de hora do que o raciocinar verbal, bem como o ritmo da temperatura leva mais tempo para se ajustar do que o ciclo sono/vigília, Hughes \& Folkard (1976).

Desempenho atlético, aqui entendido força muscular e velocidade, tende a atingir um pico no final da manhã ou no início da tarde, para Lundeen et al (1990) citados por Scott \& LaDou (1994). Diferenças na taxa de ajustamento de desempenho têm sido vistas para mudanças de avanço de fase versus atraso de fase. No estudo de Klein, Wegman \& Hunt (1972), o ajustamento mais rápido de ritmos de desempenho era visto mais freqüentemente em vôos na direção oeste do que nos vôos em direção ao leste.

Embora estudos de campo coletando dados de desempenho nas 24 horas do dia (round-the-clock) sejam difíceis de conduzir, há alguns estudos reais de desempenho de trabalho que examinam os efeitos da hora do dia, incluindo seis revistos por Folkard \& Monk (1979) segundo Scott \& LaDou (1994), que graficamente demonstraram naqueles estudos um achado consistente de mau desempenho durante o turno noturno. Os tipos de trabalhos analisados incluíam parâmetros de desempenho quanto à atenção e à vigilância, à velocidade ou à exatidão da tarefa realizada.

Um estudo com trabalhadores de turnos, controladores de processos em plantas químicas, realizado por Monk \& Embrey (1981), confirmou a importância da carga cognitiva sobre o ritmo de desempenho relatado em um estudo anterior realizado por Folkard, Monk, Knauth \& Rutenfranz (1976). O computador usado pelos controladores era ajustado para registrar automaticamente todos os erros humanos detectados pelo programa de controle de processos. $O$ menor número de erros feito pelos controladores em suas tarefas complexas de alta carga cognitiva foi detectado nas primeiras horas da manhã.

Ritmos de desempenho, para a maioria dos trabalhadores, podem ser previsiveis se o tipo de tarefa é conhecido. Em geral, para trabalhadores com orientação diurna, os trabalhos que envolvem vigilância, destreza manual, tarefas repetitivas cansativas, memória de longo termo ou tempos rápidos de reação ou que paralelizam o ritmo da temperatura serão feitos menos eficientemente em turnos noturnos, Monk \& Embrey (1981).

Por outro lado, tarefas complexas de elevada carga cognitiva, serão provavelmente melhor realizadas durante o turno da noite. Assim, diferentes tipos de tarefas têm diferentes ritmos de desempenho $e$ diferentes níveis de dependência com as alterações de tempo, ou seja, as horas do dia, de acordo com Hughes \& Fokard (1976).

Em resumo, excetuando as tarefas complexas de elevada carga cognitiva, há um bom corpo de evidência, sugerindo que o desempenho ou produtividade é pior à noite. Tempos reduzidos de reação, ou piores habilidades aritmeticomentais, são também observados nos turnos da noite.

Entretanto, trabalho recente realizado por Folkard, Totterdell, Minors et al (1993) sugere que nem todos os indicadores de desempenho são dependentes de mudanças no ritmo circadiano. $O$ autor demonstrou que o desempenho de tarefas, com um elevado componente de memória de trabalho são menos dependente de ritmo circadiano endógeno, podendo assim ser capaz de se ajustar com relativa rapidez ao trabalho noturno. Isto implica necessidade de ver a tarefa, bem como o indivíduo, ao desenhar ou preparar o sistema de turnos.

\subsection{DISTÚRBIOS NERVOSOS}

Estresse é um conceito difícil de definir e de medir, porém para Harrington (1994) há evidências de que o trabalho em turnos e noturno e as longas horas de trabalho aumentam de fato o estresse dos trabalhadores. $O$ turno da noite surge novamente como o maior responsável por níveis mais elevados de estresse.

Índices de ansiedade e depressão também foram incorporados em estudos recentes. Cole, Loving \& Kripke (1990) enfatizam que os trabalhadores de turnos $e$ noturnos são um grupo auto-selecionado e não há estudos suficientes, bem controlados, para determinar se o trabalho em turnos e noturno causa morbidez psiquiátrica ou se a auto-seleção induz trabalhadores com certos perfis psicológicos pré-existentes a se submeterem a esta forma de organização temporal do trabalho.

O trabalho em turnos e noturno parece, de fato, levar a um aumentado neuroticismo com o passar dos 
crescentes anos no sistema de trabalho em turnos $e$ noturno, mas o neuroticismo por si só pode não predizer problema de organização do trabalho relacionado com a saúde, Cole, Loving \& Kripke (1990).

Por outro lado, Bohle $\mathcal{E}$ Tilley (1993) afirmam que são as dimensões primárias de humor afetadas pelo trabalho noturno e fornece evidência preliminar com respeito a fatores predisponentes de diferenças individuais.

Outros fatores predisponentes potenciais de alterações de humor, também precisam ser sistematicamente investigados, tais como a duração do turno e boa condição física individual, as interações entre estas variáveis e fatores tais como idealização do trabalho $e$ condições físicas de trabalho, Bohle \& Tilley (1993).

\section{- 2.5 DISTÚRBIOS}

\section{GASTROINTESTINAIS}

A maioria dos autores, Fischer (1981), Minors $\mathcal{E}$ Waterhouse (1981), Moore-Ede, Sulzman \& Fuller (1982), Minors, Scott \& Waterhouse (1986), Rutenfranz, Knauth \& Fischer (1989) e Harrington (1994), concordam que distúrbios gastrointestinais, em geral, como azia e gastrite e, particularmente, ulceração péptica está associada com o trabalho em turnos e noturno.

A justificativa parece fisiologicamente válida, ou seja, horas irregulares de trabalho, más instalações de cuidados/atendimentos às necessidades à noite, disritmia circadiana e hábitos alterados de alimentação dos trabalhadores de turnos seriam, segundo Rodgers $\mathcal{E}$ Rodgers (1982), fatores predisponentes ao aparecimento de distúrbios gastrointestinais.

Para Coelho (1988) o trabalho em turnos é um fator de ordem psicossomática, que com certeza está implicado no número aumentado de úlcera péptica e este número parece guardar nítida relação com a tendência prévia do indivíduo para o desenvolvimento da doença, bem como o tempo de exposição. Para o autor, embora o trabalhador em turnos e noturno altere seus horários de trabalho os ritmos circadianos não se alteram ou se alteram parcialmente e, como conseqüência, um aumento substancial de alterações gastroduodenais é observado, tais como, dispepsias (dificuldade na digestão), colites, diarréias, constipação intestinal, etc.

Por outro lado, parece claro que os trabalhadores de turnos e noturnos têm seus hábitos alimentares alterados fazendo menos refeições, têm menos apetite e fazem mais lanches fora de hora que os trabalhadores diurnos, contribuindo para um quadro de distúrbios gastrointestinais generalizado, Oginska, Pietsch \& Oginski (1990).

Para Santos (1983) o trabalho noturno fixo ou alternado pode gerar, quando a fadiga excessiva se faz crônica e a sobrecarga ou esgotamento do hipotálamo chega a ser permanente, uma enfermidade psicossomática que se expressa por uma síndrome neurótica ou por ulceração do aparelho digestivo.

\subsection{DISTÚRBIOS CARDIOVASCULARES}

\subsubsection{Doença Cardiovascular Isquêmica}

Até 1978 os autores eram cautelosos, em associar uma maior prevalência de doença cardiovascular com trabalho em turnos e noturno. Entretanto, estudos posteriores de Knutsson, Akerstedt, Jonsson et al (1986) $e$ Waterhouse, Fokard \& Minors (1992) permitem afirmar haver maior evidência de que o trabalho em turnos e noturno está associado à doença cardiovascular. Tais estudos mostraram maior prevalência de doença cardiovascular isquêmica, independente da idade e do fumo, em trabalhadores de turnos e noturno, entretanto tal evidência só foi verificada nos últimos 10 ou 15 anos. As evidências encontradas têm apoio em trabalhos de mortalidade de Akerstedt, Alfredsson \& Theorell (1986) $e$ Teiger (1984). Inversamente, fatores de risco para doença cardiovascular isquêmica não foram encontrados em trabalhadores de turnos em um recente estudo de Bursey (1990). Porém, para Harrington (1994), o efeito das horas-extras ou das longas jornadas de trabalho tem sido investigado menos intensamente.

A hipótese de um elo entre doença cardiovascular $e$ trabalho em turnos e noturno, embora ainda não ligada com longas horas de trabalho, é suficientemente forte para que se dê séria consideração a tais práticas de trabalho como sendo um fator causal para este grupo comum de doenças, segundo Theorell (1992), Melamed, Ben-Avi, Luz et al (1995) e McNamee, Binks, Jones et al (1996). 


\subsubsection{Hipertensão Arterial}

Entre os diversos mecanismos mecânicos, cardíacos, neurais e hormonais que controlam a pressão sangüínea, Cordeiro, Lima Filho, Fischer et al (1993), Dantas \& Teixeira (1990) e Sternberg, Rosentall, Shamiss et al (1995), têm sido sugerido que o ritmo circadiano e o ritmo de nossas atividades são provavelmente determinantes do nível de pressão sangüinea.

Para Sternberg, Rosentall, Shamiss et al (1995), o trabalho em turnos e noturno fornece um ambiente conveniente para o estudo do efeito do ritmo circadiano sobre a pressão sangüinea, sendo particularmente relevante tendo em vista as pesquisas que ligam trabalhadores em turnos e noturnos a um certo número de fatores de risco de doença das artérias coronárias.

A partir dos trabalhos de Knutsson, Akerstedt, Jonsson \& Orth-Gomer (1986), citado por Sternberg, Rosentall, Shamiss et al (1995) esta hipótese obteve consistência, demonstrando o impacto que a alteração do ciclo sonol vigília possui sobre a saúde dos trabalhadores de turnos $e$ noturnos. Um percentual mais elevado de fumantes foi encontrado entre os trabalhadores de turno e mesmo com controle de idade e hábito de fumar a relação entre trabalhadores de turnos e noturno e doença das artérias permaneceu significante.

Segundo Sternberg, Rosentall, Shamiss et al (1995), trabalhadores noturnos sofrem um achatamento considerável do padrão normal de 24 horas de variáveis cardiovasculares, tais como taxa cardíaca e pressão arterial, indicando que o sistema nervoso simpático está ativo durante a noite, pois flutuações na pressão arterial $e$ atividade simpática ao longo das 24 horas estão estreitamente ligadas, como mostram Richards et al (1986) citados por Sternberg, Rosentall, Shamiss et al (1995), que observaram que a reprogramação abrupta dos trabalhadores diurnos para trabalho noturno temporário causa uma elevação nos níveis de excreção de adrenalina na urina, elevação do colesterol, da glicose, do ácido úrico e potássio no sangue, níveis estes que caíam no retorno ao trabalho diurno.

Para Imai et al (1990), citado por Sternberg, Rosentall, Shamiss et al (1995), ritmo circadiano de tônus simpático, associado com alterações nas atividades físicas e mentais, tais como o ciclo sono/vigília, parece mediar o ritmo da pressão arterial circadiana.
No estudo de Sternberg, Rosentall, Shamiss et al (1995), trabalhadores noturnos, não rodiziantes, apresentavam uma alteração de fase do ritmo circadiano da pressão arterial, e a amplitude do ritmo circadiano era menor entre os trabalhadores noturnos do que entre os diurnos, especialmente nos grupos etários mais jovens. A mudança de fase acha-se, aparentemente, relacionada com o mecanismo de adaptação e sua, magnitude fica afetada pela idade, hábitos de sono e tipo de trabalho de turno, independente de ser turno noturno fixo ou alternado, bem como com fatores fisiológicos e traços de personalidade.

Sternberg, Rosentall, Shamiss et al (1995) afirmam que a menor amplitude do ritmo circadiano da pressão arterial e da taxa cardíaca, durante os períodos de repouso entre trabalhadores noturnos não rodiziantes, possui implicações clínicas importantes. Assim, este sistema de trabalho seria menos aconselhável para trabalhadores hipertensos e que decisões terapêuticas para estes trabalhadores deveriam levar em conta o ciclo da pressão sangüínea alterado pelo trabalho noturno.

Dantas \& Teixeira (1990) encontraram uma maior prevalência de hipertensão arterial entre trabalhadores de turnos ininterruptos de revezamento - $12,1 \%$ - contra 10,3\% em trabalhadores diurnos, não havendo diferença significativa em qualquer faixa etária estudada.

\subsection{FADIGA E ACIDENTES}

Fadiga é uma queixa fundamental dos que trabalham longas horas, Akerstedt (1991). É particularmente observável no turno da noite, menos no da manhã $e$ menos ainda no da tarde.

A causa de acidentes industriais é muito complexa, entretanto parece lógico afirmar, que o estresse provocado por tensões, conflitos, emoções e rotina poderia levar a um estado de desequilíbrio orgânico e à fadiga. É possível que o trabalho em turnos leve a um estado de estresse aumentado com conseqüente desempenho prejudicado e que possa constituir numa das causas de acidentes do trabalho, Fischer (1985).

Segundo Harrington (1994), estudos sobre excesso de horas de trabalho/fadiga/acidentes não avalizam esta premissa, em grande parte porque muitos estudos têm procedimentos analíticos inadequados ou por terem fracassado em levar em conta os muitos fatores 
intervenientes que podem influenciar as estatísticas de acidentes. Para o autor, alguns estudos recentes sustentam, de fato, as alegações anteriores de que as taxas de erro são mais elevadas quando o trabalhador está mais fatigado após longas horas em trabalho noturno.

Assim, de acordo com Harrington (1994), a despeito das complexidades das causas de acidentes e dos estudos freqüentemente mal executados vistos na literatura, parece que o trabalho de turno noturno tem um desempenho $e$ recorde de segurança pior do que os outros turnos. Porém Fischer (1985), ao pesquisar acidentes de trabalho entre trabalhadores em turnos na indústria automobilística, afirma que o periodo noturno não apresenta situações que levem os empregados a se acidentarem mais do que nos períodos da manhã ou da tarde, independente dos turnos serem rodiziantes ou fixos. Para a autora, os ambientes mais tranqüilos nas empresas, maior autonomia dos grupos e confiança depositada nos trabalhadores, durante a noite, podem ser explicações para o menor número de acidentes em relação ao turno da tarde.

Por outro lado, pesquisa conduzida por Pavan (2000) em uma empresa do setor cerâmico, constatou que dos trabalhadores que tinham registro de acidente do trabalho 35,71\% apresentavam sintomas da Síndrome da Má-adaptação ao Trabalho em Turnos e que o número de trabalhadores que apresentavam acima de quatro acidentes de trabalho era $21,43 \%$.

Finalmente, é relevante ressaltar que catástrofes maiores, tais como as de Chernobyl, a da Challenger e outras, começaram todas nas primeiras horas da manhã com erros cometidos por pessoas que haviam estado em serviço por muitas horas, de acordo com Mitler, Carskadon, Czeisler et al (1988), em estudo sobre sono, catástrofes e polícia pública.

\subsection{ASPECTOS PSICOSSOCIAIS, FAMILIARES E INTERPESSOAIS}

Para Gadbois (1990), a influência dos horários em turnos e noturno sobre a vida fora do trabalho é muito menos conhecido do que se pode pensar. Considera-se que o sistema de horários pode trazer dificuldades importantes para o plano de vida familiar e social, sendo que os problemas ficam claramente evidentes após longa data.

Para o autor, a medida em que o trabalhador em turnos $e$ noturno permanece trabalhando em horários não regulares, não é somente o número de anos trabalhando neste sistema que aumenta, mas também toda uma situação social que se modifica. É o solteiro que se casa, os filhos que nascem e crescem, as condições de vida familiar mudam e novos ajustamentos devem ser feitos. Assim, desde os ajustamentos da vida cotidiana às pressões dos horários profissionais que se operam progressivamente, tudo é registrado em uma história individual.

Koller, Kundi, Haider et al (1990) demonstraram que, no que diz respeito à atitude no trabalho $e$ à satisfação no trabalho, as motivações que orientam a escolha de horário dos trabalhadores em turnos e diurnos era totalmente diferentes, sendo que os trabalhadores em turnos tinham escolhido esta forma de organização temporal do trabalho por causa de um salário mais elevado ou então porque não havia outra possibilidade profissional. Para os autores, quase a metade teria optado por um trabalho diurno se houvesse possibilidade, sendo que os trabalhadores diurnos diziam que sua preferência e escolha por este sistema de trabalho eram, antes de tudo, por causa da família e por razões de saúde. Os trabalhadores que abandonaram o sistema de trabalho em turnos e noturno o fizeram por causa de sua saúde.

No estudo desenvolvido por Koller, Kundi, Haider et al (1990), mais da metade dos trabalhadores em turnos $e$ noturnos e somente um em cada sete dos trabalhadores diurnos acreditava que havia uma relação causa/efeito entre seu trabalho e seus problemas de saúde. Os autores afirmam que somente $20 \%$ dos trabalhadores em turnos e $70 \%$ dos trabalhadores diurnos supõem poder suportar seu esquema de trabalho até a aposentadoria.

Quanto aos problemas familiares Koller, Kundi, Haider et al (1990) afirmam ser necessário salientar que em relação aos trabalhadores noturnos que passaram para horários diurnos, ou seja, os drop-outs, a proporção de divórcios era significativamente maior, sendo que a maioria dos divórcios era observada em torno dos cinco anos de trabalho contínuo em turnos e noturno.

Os trabalhadores diurnos mantêm uma forma mais consistente de segurança social, de organização familiar, da maneira da família tomar decisões e mesmo da autoridade patriarcal. Entre os trabalhadores em turnos e noturnos há uma degradação crescente e gradativa das relações sociais em família, Koller, Kundi, Haider et al (1990).

Nachreimer, Baer, Dickman et al (1985) afirmam que, sobre o ponto de vista do tempo que os trabalhadores 
em turnos e diurnos passam com as famílias e seus filhos, os primeiros dispõem substancialmente de menos lazer em momentos favoráveis à vida familiar $e$ social. Este fato acarretaria problemas, sobretudo nas famílias com filhos pequenos.

\subsection{SÍNDROME DA MÁ- ADAPTAÇÃO AO TRABALHO EM TURNOS}

A Síndrome da Má-adaptação ao Trabalho em Turnos engloba um conjunto de sintomas inespecíficos, que ocorrem em trabalhadores de turnos rodiziantes $e$, principalmente, no turno noturno fixo, como resultado da inabilidade do indivíduo para inverter seus ritmos circadianos e adaptar-se aos programas de rotação de turnos e ao trabalho noturno.

Estes sintomas em conjunto afetam em torno de 5\% dos trabalhadores, para Moore-Ede, Krieger \& Darlington (1987). Porém, até $20 \%$ das pessoas submetidas ao trabalho em turnos podem apresentar os sintomas da Síndrome da Má-adaptação ao Trabalho em Turnos, de acordo com Scott \& LaDou (1994).

Para Regis Filho \& Sell (2000), em média 12,08\% dos trabalhadores do $2^{\circ}$ turno, $22,33 \%$ do 3 o turno e $27,5 \%$ do $1^{2}$ turno apresentam pelo menos um dos sintomas de inadaptação ao trabalho em turnos e noturno, sendo que $16,67 \%$ dos trabalhadores do turno da noite e $10,34 \%$ dos trabalhadores do turno matutino manifestam sintomatologia característica da Síndrome da Máadaptação ao Trabalho em Turnos.

Com certeza pelo menos um ou alguns desses sintomas se fazem ou farão sentir no trabalhador em turnos $e$, principalmente, noturno. O que para Rutenfranz, Knauth E Fischer (1989), citando Harrington (1978), obrigará que 20 a 30\% dos trabalhadores recusem qualquer possibilidade de exercerem trabalho em turnos e noturno.

A Síndrome da Má-adaptação ao Trabalho em Turnos inclui sintomas agudos (dentro do primeiro mês) $e$ sintomas crônicos (cinco anos ou mais). Entre os sintomas agudos temos: insônia (sono diminuído e de menor qualidade), sonolência excessiva no trabalho, mal-estar, pertubações do humor, erros e acidentes aumentados, problemas familiares e sociais, o que provoca desistências precoces, Moore-Ede, Krieger \& Darlington (1987).
Os sintomas crônicos podem incluir: doenças gastrointestinais - azia, diarréia, gastrite, ulceração péptica e constipação intestinal - doença cardiovascular, desordens do sono, abuso do consumo de substâncias que podem iniciar pelo álcool ou drogas para dormir, depressão, fadiga, absenteísmo, disforia - perturbação mórbida ou mal-estar provocado pela ansiedadeseparação e divórcio, provocando abandono do trabalhador do sistema de trabalho em turnos ou mesmo a sua morte, de acordo com Moore-Ede, Krieger \& Darlington (1987).

Alguns fatores de risco são relevantes e parecem contribuir para o aparecimento e agravamento dos sintomas e incluem idade, conviver com familiares que possuem uma rotina diurna e baixa tolerância individual à ruptura do ritmo circadiano, desordens do sono, asma, diabetes mellitus, doença arterial coronária, desordens psiquiátricas, epilepsia e desordens gastrointestinais, segundo Scott \& LaDou (1994).

A Síndrome da Má-adaptação ao Trabalho em Turnos deve ser diferenciada da alteração circadiana, muito mais comum e menos severa e que ocorre ao se iniciar trabalhos em turnos e noturno ou por estarmos viajando cruzando meridianos. $O$ indivíduo, com alteração circadiana, alcança um equilíbrio com o programa, $e$ possui um nível mais baixo de sintomas.

Com o advento de viagens comerciais a jato, um número considerável de pessoas se expõe aos efeitos da mudança rápida através de meridianos ou fusos horários, o que pode desencadear uma série de sintomas, sendo que os mais comuns incluem: transtornos de sono, alterações gastrointestinais e diminuição da atenção.

A intensidade da sintomatologia depende de diversos fatores, entre eles: número de fusos horários, ou seja, quanto maior o número de fusos horários maior a sintomatologia, e da direção da viagem. Assim, mudanças no sentido do ocidente (leste/oeste) retardando as fases do sistema circadiano necessitam de um menor período de ressincronização do que as realizadas no sentido do oriente (oeste/leste), de acordo com Suarez (1990).

Os sintomas estão relacionados com a alteração transitória das inter-relações normais das fases dos diversos ritmos fisiológicos entre si e a dessincronização entre os ritmos biológicos e o meio ambiente. 
A conseqüência mais evidente da relação anormal das fases dos ritmos endógenos em relação ao meio é a insônia, resultante de uma tentativa de adormecer na fase circadiana errada, levando à perda do sono. $O$ déficit de sono junto com a tentativa do organismo de funcionar como se fosse dia em uma fase circadiana de máxima tendência para dormir e, por conseguinte, sonolência produz sintomas da síndrome de mudança rápida do ciclo sono/vigília ou jet lag (transtornos de sono, alterações gastrointestinais e diminuição da atenção).

A velocidade de adaptação a uma nova zona temporal depende de alguns elementos, de tal modo que quanto mais tempo a pessoa se expõem aos indicadores sociais, alimentares e de iluminação do novo ambiente se ressincronizar-se-á mais facilmente do que se ficar permanecendo em ambiente fechado, segundo Suarez (1990).

O paciente com a verdadeira Síndrome da Máadaptação ao Trabalho em Turnos nunca alcança um equilíbrio, pois não há uma inversão dos ciclos biológicos, Moore-Ede, Krieger \& Darlington (1987).

$O$ diagnóstico diferencial inclui: depressão endógena, abuso de substância primária, doença de úlcera péptica, síndrome de cólon irritável e desordens psiquiátricas.

Para Bittencourt \& Ritz (1987) citando Santos (1982), com a freqüencia dos transtornos psicopatológicos a manutenção do trabalhador no trabalho em turnos $e$ noturno em vez de produzir um hábito cria uma intolerância progressiva, sendo que a idade do trabalhador é um fato relevante já que ela agravaria os distúrbios e a adaptabilidade seria tanto menor quanto mais idoso for o trabalhador.

Muitos pacientes com Síndrome da Má-adaptação ao Trabalho em Turnos vão ao médico, onde são tratados apenas em seus sintomas, como por exemplo, doença de úlcera péptica, depressão ou abuso de algum tipo de substância. Isto pode lhes trazer alívio temporário, mas raramente resulta em benefício duradouro, porque a sindrome não é reconhecida. O paciente continua a estar em risco de incapacitação, ou mesmo de morte por acidente, para Moore-Ede, Krieger \& Darlington (1987).

Como o paciente não apresenta melhora duradoura da sintomatologia o "tratamento", em última instância, é a transferência médica para um programa de não-rotação de turnos, por exemplo, só durante o dia.
Freqüentemente, a direção da empresa opõe-se à transferência para tal programa de não-rotação, pois o vê como uma recompensa a um empregado que não trabalha satisfatoriamente. Tais empregados são rotulados enganosamente como sendo maus empregados ou como tendo uma má atitude.

O empregado é mal compreendido pelos supervisores, pelos amigos e mesmo pela família, enquanto seu emprego e vida familiar se deterioram. Fica financeiramente dependente deste emprego, pois o trabalho de turno rodiziante ou noturno tem melhores salários. Com o envelhecimento do empregado os sintomas se agravam, pois ele parece ter menos habilidade fisiológica para se adaptar a horários rodiziantes ou ao trabalho noturno.

Existe, ainda, uma nítida relação entre tempo de trabalho em turnos e noturno e problemas referentes ao alcoolismo, pois dados consistentes foram observados por Bittencourt \& Ritz (1987).

De acordo com Moore-Ede, Krieger \& Darlington (1987) o eventual desfecho da maioria dos indivíduos com Síndrome da Má-adaptação ao Trabalho em Turnos parece ser: a) conseguem transferência para o trabalho diurno, por terem suficiente idade e tempo de serviço; b) acidentes - por vezes fatais ou incapacitantes; c) abandono do emprego atual e a busca de outro menos bem pago, porém, em algum lugar diferente; $e d)$ demissão por mau desempenho elou abuso de substâncias.

O trabalho em turnos e noturno exerce seu maleficio sobre todos os trabalhadores, mas alguns são mais afetados pela rotação de turnos e pelo trabalho noturno do que outros. Eles geralmente passam para trabalho diurno fixo na primeira oportunidade. A princípio causam prejuízo pela despesa incorrida no seu treinamento e pelo aumento do absenteísmo.

Alguns fatores favorecem a inadaptabilidade ou adaptabilidade a este tipo de organização temporal do trabalho: a) rigidez no sono; b) habilidade para superar a sonolência; $e c$ ) alta produtividade ao amanhecer.

É importante que se analise: história médica, particularmente fatores de risco coronário, desordens gastrointestinais, epilepsia e diabetes - doenças que são adversamente afetadas pelo trabalho em turnos $e$ noturno. 
$O$ ideal é que se reorganize o trabalho no sentido de evitar o horário das 23 às 6:00 horas, não sendo possível, alguns critérios ergonômicos sugeridos pelo Setor de Ergonomia da Fundacentro (1989) devem ser observados: a) duração da jornada; b) número de equipes; c) sentido da rotação; d) horário da troca de turnos; e) média de horas trabalhadas por semana; $f$ ) número máximo de turnos noturnos consecutivos; $g$ ) número de dias consecutivos trabalhados sem interrupção; h) número de dias consecutivos de folga; i) número de folgas com sábado e domingo; j) assistência médica; l) refeições; $m$ ) exames médicos; $n$ ) férias; o) aposentadoria; $e$ p) horários diurnos.

Baseados nestes critérios a adoção de um dos tipos ou modelos de sistema de trabalhos em turnos e noturno deve ser negociada com os trabalhadores envolvidos, chefias e pessoal da área técnica como médicos, engenheiros, administradores, etc., para que as vantagens $e$ as desvantagens dos modelos para aquela situação concreta sejam devidamente analisadas e que todos os envolvidos, tanto trabalhadores como membros da família, tenham pleno conhecimento dos detalhes e da escala do sistema escolhido. Entretanto, o trabalho em turnos, principalmente noturno, deve ser evitado, pois qualquer que seja o sistema de turnos trará algum prejuizo à saúde do trabalhador.

\section{CONCLUSÃO E RECOMENDAÇÕES}

A maioria dos trabalhadores não gosta do trabalho em turnos e noturno, a literatura confirma que esse tipo de organização temporal do trabalho não é benéfico para a saúde física, psíquica e emocional do trabalhador, criando também, interferências nas estruturas temporais, sociais e familiares podendo os problemas se acentuar com a duração da exposição e a idade dos indivíduos submetidos a este sistema de trabalho.

O fato de mais da metade dos trabalhadores do turno da noite preferir permanecer neste horário parece estar mais

relacionado com o adicional noturno a que têm direito e com a ausência de supervisão constante e intensa, pois os ajustes na produção são feitos durante os turnos diurnos, do que com a possível tolerância do trabalhador ao turno noturno.

Parece evidente que não existe uma solução única e ideal para os sistemas de turnos. $O$ que existe são soluções melhores ou piores para os trabalhadores, dependendo se houver ou não uma preocupação de seguir critérios ergonômicos no estabelecimento da escala de turnos e na análise concreta da situação de trabalho.

Assim, antes de recomendar para uma empresa um novo esquema de sistema ou modelo de turnos de trabalho, a complexidade de variáveis que envolvem o trabalho em turnos e noturno deve ser reconhecida fazendo-se um estudo de larga escala sobre aspectos pessoais, sociais e de saúde.

É necessário que haja cooperação, consulta e concessões entre os parceiros sociais, ou seja, para adequar horários de trabalho e estratégias individuais de superação.

Porém, algumas linhas principais merecem ser consideradas: a) limitar o trabalho noturno onde possivel; b) se isto não for possivel, o turno em rotação rápida para diante é a melhor opção, já que o trabalho noturno fixo raramente é uma solução aceitável; c) iniciar o turno matutino preferencialmente depois das 6:00 horas; $e$ d) permitir pelo menos um dia de descanso, sendo preferivel dois, entre mudanças de turno, garantindo sempre que possivel que alguns desses dias coincidam com os fins de semana.

Por outro lado, algumas ações não dependem do sistema de turnos adotado e podem ser implementadas: a) melhorias no local de trabalho - como praça de alimentação durante as 24 horas, supervisão e níveis de produção que privilegiem as características de cada turno; b) disponibilizar melhores cuidados de saúde incluindo exames médicos periódicos direcionados para a problemática do trabalho em turnos e noturno; e c) facilitar transporte acessivel e instalações de recreio adequadas, já que as mesmas são geralmente ruins nos turnos que incluam períodos noturnos.

Entretanto, mais estudos são necessários para identificar quais aspectos do trabalho em turnos e noturno e de saúde são mais dependentes de características individuais e se acompanhamentos longitudinais poderiam identificar quais desses trabalhadores são "intolerantes" ao trabalho em turnos e noturno e, principalmente, por quais razões.

Finalmente, é preciso determinar a eficiência e a utilidade de certas estratégias como luz brilhante durante o turno da noite para melhorar a adaptação do ritmo circadiano ao trabalho em turnos, como sugerem pesquisas realizadas por Eastman, Stewart, Mahoney et 
al (1994), uso de agentes terapêuticos como comprimidos de melatonina e mais recentemente o Modafinal para tratar perturbações do sono provocadas pelo trabalho em horários irregulares e a permissão para fazer "sonecas" durante o trabalho.

\section{REFERÊNCIAS BIBLIOGRÁFICAS}

ANDLAUER, P., FOURRE, L. Le travail en e'quipes alternantes. etude la nuisance comparee de deux modalities d'alternance. Re. Franc. Trav. Paris, v. 19, p.35-51, 1965.

ARECHIGA, H. Ritmos circadianos y ultradianos. Gac. Med. Mexico. Cidade do México, v. 124, n. 3-4, p.58-62, Mar./ Abr. 1988.

ARKERSTEDT, T., ALFREDSSON, L., THEORELL, T. An aggregate study of irregular work hours and cardiovascular disease. In: INTERNATIONAL SYMPOSIUM ON NIGHT AND SHIFT WORK, 7, 1986, Peter Lang. Anais... Peter Lang, 1986. v. 31.

ARKERSTEDT, T. Sleepness at work: effects of irregular work hours. In: MONK, T. H. (Ed). Sleep, Sleepness and Performance. New York: John Wiley, 1991. p.129-152.

BITTENCOURT, L. A. K., RITZ, M. R. de C. Conseqüências do trabalho em turnos para a saúde dos trabalhadores de uma empresa do setor de energia. In: CONGRESSO DA ASSOCIAÇÃO NACIONAL DE MEDICINA DO TRABALHO, 5, 1987, Florianópolis. Anais... Florianópolis, 1987. p.707-739.

BOURLIÈRE, F., PACAUD, S. Travai et vieillissement. In: SCHERRER, J.Préc. de Physiol. Trav. Paris: Masson, 1981.p.540-570.

BOHLE, P., TILLEY, A. J. Predicting mood change on night shift. Ergonomics, London, v. 36, n. 1-3, p.125-133, 1993.

BRUGNE, J. F. Effects of night work on circadian rhythms and sleep. Prof-Nurse., London, v. 51, n . 1, p.25-28, Out. 1994.

BURSEY, R. g. A cardiovascular study of shiftworkers with respect to coronary artery disease risk factor prevalence. $L$ Soc. Occup. Med.. London, v. 40, n. 2, p.65-67, 1990.

CASTRO, A. P. Jr. Corpo saudável. Proteção, São Paulo, 1995. Out. p. 8-43.

CHADE, H. O. El ciclo sueño-vigilia. Neurofisiologia y clasificacion clinica. R. Fac. Ci. Med. Univ. Nac. Cuyo, Cuyo, v. 8, n. 3, p.34-43, 1986.
CHAVES, E. C. O trabalho noturno. In: VIEIRA, S. I. (ed). Medicina Básica do Trabalho. Curitiba: Genesis. 1995. p.129-140.

CIPOLLA-NETO, J., MARQUES, N., MENNA-BARRETO, L. (Eds). Introdução ao estudo da cronobiologia. São Paulo: Ícone/EDUSP, 1988.

CIPOLLA-NETO, J., NEGRÃO, N., AFECHE, S. C. et al. Remarkable similarities between the temporal organization of neocortical electrographic sleep patterns of rats and humans. Braz. J. Med. Biol. Res.. São Paulo, v. 21, n. 3, p.599-601, 1988.

COELHO, P. R. L. Estudo da doença gastroduodenal nos trabalhadores de turno em indústria de papel. Serviço da Indústria do Papel. Papelão e Cortiça do Estado de São Paulo, São Paulo, 1988. p.92-113.

COLE, R. J., LOVING, R. T., KRIPKE, D. F. Psychiatric aspects of shiftwork. Occup. Med: State of The Art Reviews, New York, v. 5, n. 2, p.301-314, 1990.

CORDEIRO, R., LIMA FILHO, E. C., FISCHER, F. M. et al. Associação da pressão arterial diastólica com o tempo acumulado de trabalho entre motoristas e cobradores. $\underline{\text { Re. }}$ de Sau. Pub., São Paulo, v. 27, n. 5,p.363-372, Out. 1993.

DANTAS, J., TEIXEIRA, J. W. Fatores de risco coronariano em trabalhadores de turnos ininterruptos de revezamento. $\underline{S O}$ S Sau. Ocu. Seg.. São Paulo, n. 1, p.6-20, 1990.

DeLUCIA, R., PLANETA, C. da S., SIMÕES, N. A. et al. Trabalho em turno: consumo de medicamentos, bebidas alcoólicas e tabaco por operários de Cubatão - SP. $\underline{\text { R. Bras. }}$ Sau. Ocu.. São Paulo, v. 16, n. 64, p.51-3, Out./Dez. 1988.

EASTMAN, C. I., STEWART, K. T., MAHONEY, M. P. et al. Dark goggles and bright light improve circadian rhythm adaptation to night-shift work. Sleep. Chicago, v. 17, n. 6, p.535-543, 1994.

FALZON, P. Des objectifs concrète et ergonomie. (ed). DANIELLOU, F. L'ergonomie en quête de ses principes. débats épistémologiques. Toulouse: Octares, p.233-242, 1996.

FERREIRA, L. L. Sono de trabalhadores em turnos alternantes. Rev. Bra. Sau. Ocu, São Paulo, v. 13, n. 51, p.25-27, Jul./ Set. 1985.

Melhores condições para o trabalho em turno alternantes. Fundacentro Atualidades em Prevenção de Acidentes, São Paulo, v. 16, n. 158, p.10, Ago.1985. 
Régis Filho, G. I. - Síndrome da Má-Adaptação ao Trabalho em Turnos - uma Abordagem Ergonômica

Trabalho em turnos: temas para discussão. R. Bra. Sau. Ocu., São Paulo, v. 15, n. 58, p.27-32, Abr./ Jun. 1987.

FISCHER, F. M. Trabalho em turnos: alguns aspectos econômicos, médicos e sociais. $\mathrm{R}$. Bra. Sau. Ocu. São Paulo, v. 9, n. 36, p.1-40, Out./Dez. 1981. Suplemento.

Trabalho em turnos: absenteísmo e acidentes. Fundacentro Atualidades em Prevenção de Acidentes, São Paulo, v. 16, n. 157, p.4, Jul. 1985.

Acidentes de trabalho entre trabalhadores em turnos de indústrias automobilísticas. Rev. Bra. Sau. Ocu. São Paulo, v. 13, n. 52. p.34-59, Out./Dez. 1985.

FISCHER. F. M., LIEBER, R. R., BROWN, F. M. Trabalho em turnos e as relações com a saúde-doença. p.545-572. 1992.

FISCHER, F. M., BERWERTH, A., BRUNI, A. de C. B. et al. $A$ organização do trabalho em turnos e repercussões no sono de trabalhadores petroquímicos. $\underline{R}$. Bras. Sau. Ocu.. São Paulo, v. 21, n. 78, p.33-49, Abr./Jun. 1993.

Modificações psicofisiológicas ocorridas entre trabalhadores do setor petroquímico. In: CONGRESSO LATINO-AMERICANO E SEMINÁRIO BRASILEIRO DE ERGONOMIA, 2, 1993. Florianópolis. Anais... Florianópolis, 1993. p.257-259.

FLORES-LOZANO, J. A. Aspectos psicológicos da fadiga. Rev. Bra. Sau. Ocu, SãoPaulo, v. 29, n. 8, p.52-56, Jan./Mar. 1980.

FOLKARD, S. Diurnal variation in logical reasoning. $\mathrm{BrI}$ Psychol. Leicester, v. 66, p.1-8, 1975.

FOLKARD, S., MONK, T. H. Circadian rhythms in human memory. Br I Psychol.v. 71, p.295-307, 1980.

FOLKARD, S., TOTTERDELL, P., MINORS, D. et al. Dissecting circadian performance rhythms: impliocations for shiftwork. Ergonomics, London, v. 36, p.307-331. 1993.

FORET, J. Sommeil, vieillissement et horaires alternants. In: ANDLAUER, P. et al. Ergonomie du Travail de nuit et des horaires alternants. Paris, p.135-142, 1977.

FORET, J., BENSIMON, G., BENOIT, O. Quality of sleep as a function of age and shiftwork. In: REINBERG A., VIEUX, N., ANDLAUER, P. Night and shift work: biological and social aspects. Oxford: Pergamon Press, 1981.

FORET, J. To what extent can sleep be influenced by diurnal activity. Experientia, Paris, v. 40, p.422-425, 1984.

Les apports de la chronobiologie aux problèmes posés par le travail posté. Trav. Hum.. Paris, v. 55, n. 3, p.237$257,1992$.

FRAISSE, P. Eléments de chronopsychologie. Trav. Hum.. Paris, v. 43, n. 2, p.353-372, 1980.

FUNDACENTRO. Setor de Ergonomia. Trabalho em turnos: qual a melhor solução. Fundacentro Atualidades em Prevenção de Acidentes, São Paulo, v. 20, n. 234, p.8-13, Jun. 1985.

FUNDACENTRO. Setor de Ergonomia. Trabalho noturno na ordem do dia da $77^{a}$ Conferência da OIT. Fundacentro Atualidades em Prevenção de Acidentes, São Paulo, v.21, n. 248, p.6-10, Ago. 1990.

GADBOIS, C. Women on night shift: interdependence os sleep and off-the-job activities. In: REINBERG A., VIEUX, N., ANDLAUER, $P$. Night and shift work: biological and social aspects. Oxford: Pergamon Press, 1981.

GADBOIS, C., QUEINNEC, Y. Travail de nuit, rythmes cirdadiens et régulation dês activités. Trav. Hum. Paris, $v$. 47, n. 3, p.195-225, 1984.

GADBOIS, C. L'exacte mesure des situations de travail posté: au-dela dês Similitudes formelles, des réalités différentes. Trav. Hum.. Paris, v. 53, n. 4, p.329-345, 1990.

Travail posté et vie sociale recherches actuelles et perspectives. Trav. Hum., Paris, v. 53, n. 2, p97-101, 1990.

GORDON, N. P., CLEARY, P. D., PARKER, C. E. et al. The prevalence and health impact of shiftwork. 1990.

GUYTON. A. C. Fisiologia humana. 6. ed. Rio de Janeiro: Guanabara Koogan, p.457-483, 1991.

$H A A N, E$. de, JANSEN, B. The differential effects of rotas on psychosocial well-being: a time-budget study. Trav. Hum.. Paris, v. 53, n. 2, p.139-152, 1990.

HÄRMÄ, M. I., HAKOLA, T., AKERSTEDT, T. et al. Age and adjustment to night work. Occupational na Enviroment Medicine, London, v. 51, n. 8, p.568-573, Aug. 1994.

HARRINGTON, J. M. Shift work and health - a critical review of the literature on working hours. Acad. Med. Singapore, Singapore, v. 23, n. 5, p.699-705, Sept.1994.

HUBERMAN, L. História das riquezas do homem. 21. ed. rev. Rio de Janeiro: Editora Guanabara, 1986. 313p.

HUGHES, D. C., FOLKARD, S. Adaptation to an 8-hour shift in living routine by members of a socially isolated community. Nature, London, v. 264, p.432-434, 1976.

KLIEN, K. E., WEGMAN, H. M., HUNT, B. I. 
Desynchronization as a function of body temperature and performance circadian rhythm as a result of outgoing and homecoming transmeridian flights. Aerospace Med, v .43, p.119-132, 1972.

KNUTSSON, A., ALKERSTEDT, T., JONSSON, B. et al. Increased risk of Ischemic heart disease in shift workers. Lancet, London, v. 12, p89-92, 1986. homecoming transmeridian flights. Aerospace Med, v .43, p.119-132, 1972.

KNUTSSON, A., ALKERSTEDT, T., JONSSON, B. et al. Prevalence of risk factors for coronary artery disease among day and shift workers. Scand I Work Environ. Health. Helsinki v. 14, p.317-321, 1988.

KNUTSSON, A. Shiftwork and coronary heart disease. Scand LInt Med., v. 44, p.1-36, 1989.

KOLLER, M., KUNDI, M., HAIDER, M. et al. Changements survenus en cinq ans dans la vie familiale, la satisfaction et la santé de travailleurs postés. Trav. Hum.. Paris, v. 53, n. 2, p.154-174, 1990.

McNAMEE, R., BINKS, K., JONES, S. et al. Shiftwork and mortality from Ischaemic disease. Occup. Environ. Med., London, v. 53, n. 6, p.367-373, Jun.1996.

MAURICE, M. Shift work-economics advantages and social costs. International Labour Office, Geneva, 1975.

MEIJMAN, T. F. Analyse subjective de la récupération après les postes de nuit dans le cas de rotation lente (7 jours). Trav. Hum.. Paris, v. 44, n.2, p.315-323, 1981.

MELAMED, S., BEN-AVI, I., LUZ, J. et al. Repetitive work, work underload and coronary hearty disease risk factors among blue-collar workers - the CORDIS study. cardiovascular ocupacional risk factors determination in israel. L-Psychosom-Rs, London, v. 39, n. 1, p.19-29, Jan. 1995.

MINORS, D. S., WATERHOUSE, J. M. Circadian rhythms and the human, Boston, Wright, PSG, 1981.

MINORS, D. S., SCOTT, A. R., WATERHOUSE, J. M. Circadian arrhythmia: shiftwork, travel, and health. LSoc. Occup. Med., v. 36, n. 2, p.39-44, 1986.

MITLER, M. M., CARSKADON, M.A., CZEISLER, C. A. et al. Catastrophes, sleep, and public policy: Consensus Report. Sleep. Chicago, v. 11, p.100-109, 1988.

MONK, T. H., FOLKARD, S. Concealed inefficiency of latenight study. Nature, London, v. 273, p.296-297, 1978.
MONK, T. H., EMBREY, D. E. A field study of circadian rhythms in actual and interpolated task performance. In: REINBERG A., VIEUX, N, ANDLAUER, P. Night and shift work: biological and social aspects. Oxford: Pergamon Press. 1981.

MOORE-EDE, Martin C., SULZMAN, F., FULLER, C. The clocks that time us. Cambridge, Mass, Havard University Press, 1982.

MOORE-EDE, M. C. Shiftwork and your health, 1983.

MOORE-EDE, Martin C., KRIEGER, G. R., DARLINGTON, A. C. Shiftwork maladaptation syndrome: etiology, diagnosis and management. Notes from the American Occupational Medical Associaton, Postgraduate Seminar, $v$. 12, Apr. 27, 1987.

MORENO. C. R.de C. Critérios cronobiológicos na adaptação ao trabalho em turnos alternantes. validação de um instrumento de medida. São Paulo. Dissertação (Mestrado em Saúde Pública) - Faculdade de Saúde Pública, Universidade de São Paulo, 1993, 70p.

NACHREINER, F. BAER, K., DIEKMAN, A. et al. Some new approaches in the analysis of interferences of shiftwork with social life. In: WEDDERBURN, A., SMITH, $P$. Psychological approaches to night and shiftwork. Edinburgh: Heriot-Watt University, v. 4, p.1-34, 1984.

OGINSKA, H., PIETSCH, E., OGINSKI, A. L'horaire de repas chez posté: aspects psychosoiaux. Une enquête das líndustrie sidérurgique polonaise. Trav. Hum. Paris, v. 53, n. 3, p.245-251, 1990.

OLSEN, O., KRISTENSEN, T. S. Impact of work environment on cardiovascular diseases in denmark. L. Epidemiol. Community Health London, v. 45, p.4-9, 1991.

PATRÍCIO, Z. M. Ser saudável. uma abordagem ética e estética pelo cuidado holístico-ecológico. Florianópolis: Editora Universitária. 1996, 153p.

PAVAN, A. L. A influência da sindrome da má-adaptação ao trabalho em turnos na ocorrência dos acidentes do trabalho - um estudo de caso. 2000. Florianópolis. Dissertação de Mestrado (Programa de Pós-Graduação em Engenharia da Produção). UFSC, 2000.

RANG, H. P., DALE, M.. M. Farmacologia. 2. ed. Rio de Janeiro: Guanabara Koogan, p.289-324, 1991.

REGIS, G. I. F. Síndrome da maladaptação ao trabalho em turnos - uma abordagem ergonômica. Dissertação de Mestrado. Florianópolis. UFSC, 1998, 101p. 
REGIS FILHO, G. I., SELL, Ingeborg. Síndrome da máadaptação ao trabalho em turnos - uma abordagem ergonômica. Itajaí: Editora da UNIVALI. 2000, 132p.

REINBERG, A., CHAUMONT, A. J., LAPORT, A. et al. Mémories. étude chronobiologique des effets des changements d'horaires de travail (autométrie de 20 sujets postés; système des $3 \times 8$ à rotation hebdomadaire. Arc. Mal. Prof., Méd. Trav. Sêc. Soc., Paris, v. 35, n. 3, p.373-392, Mar, 1973.

REINBERG, A., ANDLAUER, P., VIEUX, N. Tolérance du travail posté: une approche chronobiologique. Trav. Hum. Paris, v. 44, n. 1, p.55-69, 1981.

RODGERS, F. R., RODGERS, C. Business and the facts os family. Harv. Bus. Re. Boston p.121-129, 1989.

RUTENFRANZ, J., KNAUTH, P., FISCHER, F. M. Trabalho em turnos e noturno. São Paulo: Editora Hucitec. 1989. $135 p$.

SANTOS, L. A. M B. dos. Considerações sobre trabalho noturno. Eletrobrás - Temas de Saúde Ocupacional. Brasília, n. 22, p.1-19, 1983.

SCOTT, J. A., LaDOU, J. Health and safety in shift workers. In: ZENZ, C. Occupational Medecine. 3. ed. St. Louis: MOSBY. 1994. p.960-986.

SILVA FILHO, J. L. F. da, TURNES, U. M. Trabalho em turnos. In: VIEIRA, S. I. (Ed). Medicina Básica do Trabalho. Curitiba: Genesis. 1995. p.119-127.

STERNBERG, H., ROSENTHAL, T., SHAMISS, A. et al.Altered circadian Rhythm of blood pressure in shift workers. L. Hum. Hypertens., Tel Aviv, v. 9, p.349-353, 1995.

SUAREZ, E. O. Ritmos circadianos: implicaçōes clínicas. In: Reimão, R. (ed) Sono: aspectos atuais. 1990. p.237-248.

TAMKINS, T. Shiftwork may raise heart-attack risk. [1996]. Endereço eletrônico WWW.URL:_http:// www.medscape.com/textSearch.

TAVEMIER, G. Mundo en sombras del turno de la noche. Int. Management, Madri, p.37-42, Nov./Dez. 1978.

TEIGER, C., LAVILLE, A., LORTIE, M. et al. Travailleurs de nuit permanents rythmes circadiens et mortalité. Trav. Hum.. Paris, v. 44, n. 1, p.71-90, 1981.

$T E I G E R, C$. Over mortality among permanent nightworkers: some questions about adaptation. In: WEDDERBURN, A., SMITH, P. (Eds). Psychological Approaches to Night and Shift Work. Edinburg: Heriot-Watt University, v. 15, n. 1, p.15-34, 1984.
THEORELL, T. The psycho-social environment stress and coronary heart disease. In: MARMOTT, M., ELLIOTT, P. (Eds) Coronary Heart Disease Epidemiology. Oxford: Oxford University Press, p.256-273, 1992.

THIIS-EVENSEN, E. Shiftwork and health. In. Med. Surg, $v$. 27, p.493-497, 1958.

WAGNER, J. Shiftwork and mining. an overview of history and development. Bureau of Mines, Twin Cities Research Center, Minneapolis, MN, Sept. 1984.

WEIBEL, L. BRANDENBERGER, G., GOICHOT, B. et al. The circadian thyrotropin rhythm is delayed in regular night workers. Neurosci. Lett., Limerick, v. 187, p.83-86, Mar. 1995.

WATERHOUSE, J. M., FOLKARD, S., MINORS, D. S. Shiftwork health and safety. an overview of the scientific literature 1978-1990. London: HMSO, 1992. HSE Research Report. Cap. 31, 1992.

WHITE, L., KEITH, B. The effect of shift work on the quality and stability of marital relations. L. Marriage Family v. 52, May. 1990.

WINGET, C., HUGHES, L., LADOU, J. Physiological effects of rational work shifting. 1994.

ZANINI, A. C., OGA, S. Farmacologia aplicada. 3. ed. São Paulo: Atheneu Editora, p.449-487, 1985. 